\title{
Detection of Aflatoxin and Ochratoxin A in Spices by High-Performance Liquid Chromatography
}

\author{
Zahra Zareshahrabadi, ${ }^{1}$ Robab Bahmyari, ${ }^{1}$ Hasti Nouraei $\mathbb{D}^{1},{ }^{1}$ Hossein Khodadadi, ${ }^{1}$ \\ Pouyan Mehryar, ${ }^{2}$ Fatemeh Asadian, ${ }^{3}$ and Kamiar Zomorodian $\mathbb{D}^{1,4}$ \\ ${ }^{1}$ Department of Medical Mycology and Parasitology, School of Medicine, Shiraz University of Medical Sciences, Shiraz, Iran \\ ${ }^{2}$ Institute of Design, Robotics, and Optimisation, School of Mechanical Engineering, University of Leeds, Leeds, UK \\ ${ }^{3}$ Department of Pathology, Shiraz University of Medical Sciences, Shiraz, Iran \\ ${ }^{4}$ Basic Sciences in Infectious Diseases Research Center, Shiraz University of Medical Sciences, Shiraz, Iran
}

Correspondence should be addressed to Kamiar Zomorodian; zomorodian@sums.ac.ir

Received 3 August 2020; Revised 20 October 2020; Accepted 25 November 2020; Published 12 December 2020

Academic Editor: Alessandra Durazzo

Copyright ( 2020 Zahra Zareshahrabadi et al. This is an open access article distributed under the Creative Commons Attribution License, which permits unrestricted use, distribution, and reproduction in any medium, provided the original work is properly cited.

\begin{abstract}
Background. Spices are one of the flavoring components of food in the cooking recipes of different nations that are used daily. However, these ingredients may be contaminated by toxicogenic fungi and subsequent production of mycotoxins that cannot be neutralized through cooking. In the present study, the possible contamination of spices by aflatoxins (AFs) and ochratoxin A (OTA) was investigated from Shiraz, the south part of Iran. Materials and Methods. A total of 80 spice samples including turmeric $(n=20)$, red pepper $(n=20)$, black pepper $(n=20)$, and cinnamon $(n=20)$ were purchased from markets and cultured on appropriate medium. The isolated fungi were identified. Simultaneously, mycotoxins from spices were extracted with immunoaffinity columns (IAC) and the occurrence of AFs $(B 1+B 2+\mathrm{G} 1+\mathrm{G} 2)$ and OTA was then determined using high-performance liquid chromatography (HPLC) with a fluorescence detector (FD). Result. The results depicted that 40 spice samples were contaminated with AFs and 48 samples with OTA. The highest rate of AFs contamination was related to red pepper, in $80 \%$ of which the amount of contamination was excessive than the standard level $(>10 \mu \mathrm{g} / \mathrm{kg})$. All black pepper samples were determined to be contaminated with OTA at over legislation limits of $>15 \mu \mathrm{g} / \mathrm{kg}$. Aspergillus species were the predominant isolated fungi, followed by Penicillium, and Mucor species. Discussion. Regarding the high mycotoxins contamination in spices in the current study, regular effective surveillance and quality control procedures are highly recommended. To achieve this goal, it is necessary to empower food-related laboratories with precise methods of isolation and detection of mycotoxins.
\end{abstract}

\section{Introduction}

Spice is a part of the plant, such as the leave, bark, seed, fruit, or root, which is used for coloring, flavoring, and even for preserving food [1]. Each spice has its unique chemical constituents which improve the flavor of the meal and create a specific sensation. In the Mediterranean and Middle East regions, spices are used daily for casual cooking to enhance the natural flavor of food. Among the different spices, black pepper, chili powder, cinnamon, and turmeric are widely used in all around the world and considered an inseparable part of Persian food recipes. Black pepper, known as the king of spices, is grown in tropical regions and is the most economical and consumed item in food. Black pepper fruit, also known as black pepper seed, is a premature bean grass that dries in the dark, after being exposed to sunlight [2]. This spice is indigenous to India; it is valued for the spectacular nature of its burning, which is attributed to the alkaloid piperine [3]. Black pepper is used not only in the preparation of food, meat products, soups, vegetables, and marinades as a spice but also for other purposes, such as in the pharmaceutical industry and perfumery and as a preservative [4]. Chili, also called red pepper, belongs to the genus Capsicum of the Solanaceae family [5]. Chili red 
pepper has the highest consumption rate worldwide right after black pepper. Capsaicin is an alkyl-amide that is the main constituent of red pepper [6]. Cinnamon is a tree belonging to the genus Cinnamomum [5]. Cinnamon has been used in different cultures for centuries as the flavors of flavors. The countries of Indonesia, China, Sri Lanka, and Vietnam are amongst the largest producers and suppliers of this spice. In addition to cooking, this spice has other properties such as being a disinfectant, as a solution for diarrhea, a stimulant, for reducing fevers, and as an antifungal [7]. Turmeric is derived from the root of Curcuma longa L., a yellow spice that is commonly used in the Indian subcontinent and cultivated in Southern and Southeast Asia. It is the main constituent of a well-known spice, named curry. This spice is used for flavoring, coloring, and adding flavor to food, as well as for its preservative and antioxidant properties $[8,9]$. It was also used as a traditional medicine to treat various disorders, such as gas, colic, toothache, chest pain, menstrual problems, stomach and liver problems, and wounds healing [9]. Generally, Asia contributing to total global spice production is $95.1 \%$ followed by Africa $(2.9 \%)$, America (1.5\%), and Europe (0.5\%). Iran is one of the main importers and consumer of spices, worldwide. Most of the spices in the Persian market are imported from abroad and might be contaminated with fungi. Mycotoxins are byproducts of some of these fungi which are known to pose as potential health hazards for humans. The worldwide contamination of foods and feeds with these toxins is a significant problem and may be occurred during pre- or postharvest, storage, processing, and packing stages [10]. These toxins may cause minor to major effects, including skin necrosis, leukopenia, immunodeficiency, and even liver cancer [11]. Due to the nonprotein structure of these toxins, they are often resistant to heat and might compromise the health of those consuming such contaminated foods, despite the cooking process.

Currently, more than 300 mycotoxins are known, scientific attention is focused mainly on those that have proven to be carcinogenic and/or toxic. Among the various mycotoxins, aflatoxins (AFTs) and ochratoxin A (OTA) have attracted a great concern due to their adverse effects and agroeconomic significance. These mycotoxins account for millions of dollars annually in losses worldwide in human and animal health and damage agricultural products [12]. Aflatoxins are mycotoxins produced by some members of the Aspergillus section Flavi including $A$. flavus, A. parasiticus, and A. nomius. The major AFs are B1, B2, G1, and G2, which can be differentiated under fluorescent and violet lights (green or blue) and the relative chromatographic movements, through thin layer chromatography (TLC) [13]. In this family, AFB1 is a well-known toxin, with mutagenic and carcinogenic properties for both humans and animals [14]. Aflatoxin contamination in spices is a serious worldwide concern affecting international trade. Regarding the Rapid Alert System for Food and Feed (RASFF) in 2016, mycotoxins were recorded as the first main hazard in border rejection notifications in the European Union [5]. The acceptable concentration of these toxins varies $10 \mu \mathrm{g} / \mathrm{kg}$ for total AFTs, and $15 \mu \mathrm{g} / \mathrm{kg}$ for OTA in Iceland, to $20 \mu \mathrm{g} / \mathrm{kg}$ for total AFTs and $30 \mu \mathrm{g} / \mathrm{kg}$ for OTA in Brazil [15]. In Iran, the acceptable level of AFTs for spices has been set at five for AFB1 and 10 for total AFs (B1+B2+G1+G2) [15]. Ochratoxin $\mathrm{A}$ is another mycotoxin with poisonous effects on the kidney [16] and is primarily produced by Aspergillus ochraceus and Penicillium verrucosum [17].

Since most spices are mainly produced and imported from few Asian countries with hot and humid climates, the possibility of contamination with toxicogenic fungi during the process of transportation and storage is relatively high. Due to the importance of the level of aflatoxins and ochratoxin A in food quality and public health $[18,19]$, the amount of these two toxins in spices (black pepper, red pepper, cinnamon, and turmeric) were detected by HPLC.

\section{Materials and Methods}

2.1. Materials. A total of 80 spice samples in commercially available sizes (40-100 g) were randomly purchased from supermarkets from October to November 2019. The collected spices included red peppers (20 samples), black pepper (20 samples), turmeric (20 samples), and cinnamon (20 samples).

2.1.1. Screening of Fungi. Five grams of each spice sample was added to $50 \mathrm{ml}$ of sterile distilled water, containing $0.05 \%$ tween 80 . After shacking with the vortex for 15 seconds, $100 \mu \mathrm{l}$ of this suspension was inoculated onto the Dichloran Rose-Bengal Chloramphenicol agar (Sigma Chemicals) and the Aspergillus flavus-parasiticus agar mediums (Sigma Chemicals, USA), using the spread plate method [18]. The plates were then incubated at $25-28^{\circ} \mathrm{C}$ for 5-7 days. The isolated colonies were then subcultured and identified by their morphological characteristics, followed by the taxonomic schemes of Maren [19] for the genera Aspergillus, [20] Penicillium, [21] Mocur, and other genera [22] (Figure 1).

\subsection{Methods}

2.2.1. Aflatoxins Determination. A stock solution of AFB1, AFG1 $(1000 \mu \mathrm{g} / \mathrm{kg})$ and AFB2, AFG2 $(200 \mu \mathrm{g} / \mathrm{kg})$ was dissolved in benzene-acetonitrile $(98: 2, \mathrm{v} / \mathrm{v})$, purchased from Supelco (Bellefonte, PA, USA). The working standard solution $(500 \mu \mathrm{g} / \mathrm{kg})$ for each mycotoxin was prepared, kept in an amber vial, and stored at $-20^{\circ} \mathrm{C}$ until used. The AFs' standard calibration curves for HPLC determination were prepared by dissolving an appropriate amount of working standard solution in the same solvent to obtain the final concentration. The glass microfiber filter BOECO $(15 \mathrm{~cm}$, 934-AH), fluted filter paper $(24 \mathrm{~cm})$, methanol, acetonitrile (HPLC grade), and sodium chloride were purchased from Merck (Darmstadt, Germany). Immunoaffinity columns for AFs were purchased from Libios (Pontcharra-sur-Turdine, France); the decontamination of the glassware was performed using a sodium hypochlorite solution and washing it to a neutral $\mathrm{pH}$ with distilled water. 


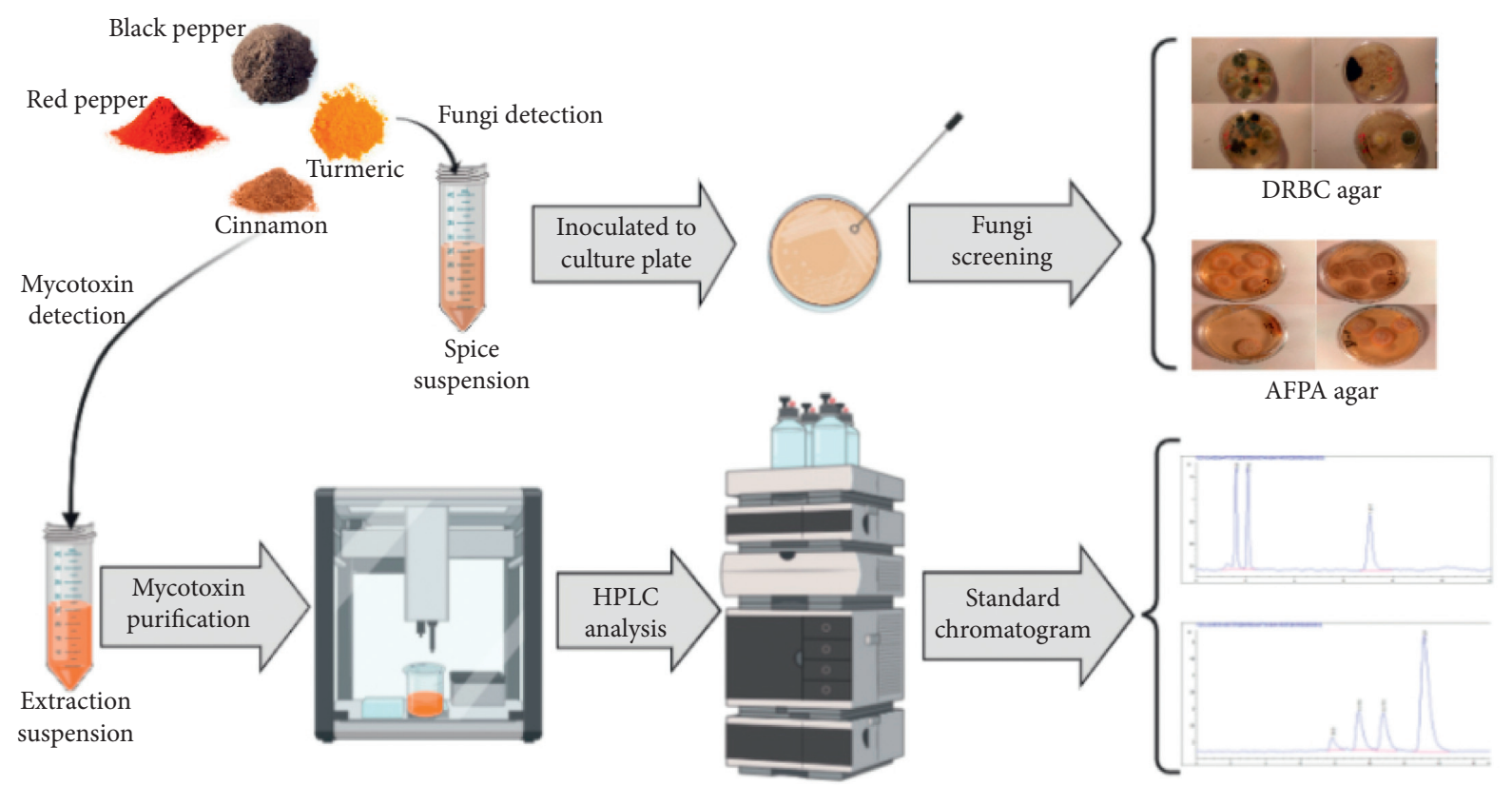

Figure 1: Graphical scheme of analytical methods for the determination of aflatoxin and ochratoxin in spices.

2.2.2. Ochratoxin A Determination. HPLC grade acetonitrile, acetic acid glacial, and sodium chloride were purchased from Merck (Darmstadt, Germany), and the OTA $(1000 \mu \mathrm{g} /$ $\mathrm{kg}$ ) was obtained from Supelco (Bellefonte, USA). A standard working solution of OTA $(100 \mu \mathrm{g} / \mathrm{kg})$ was prepared by evaporating a known volume of the stock solution under a nitrogen stream, followed by dissolving it in methanol-water $(50: 50, \mathrm{v} / \mathrm{v})$. The IAC for the OTA, the glass microfiber filter BOECO $(15 \mathrm{~cm}, 934-\mathrm{AH})$, and the fluted filter paper $(24 \mathrm{~cm})$ were obtained from Germany. Phosphate-buffered saline (PBS) was prepared by adding the following chemicals to one liter of water: anhydrous dibasic sodium phosphate $(2.04 \mathrm{~g})$, sodium chloride $(87.9 \mathrm{~g})$, and sodium dihydrogen phosphate monohydrate $(12.62 \mathrm{~g}) .100 \mathrm{ml}$ of this solution was diluted, and the $\mathrm{pH}$ was adjusted to 7.4 with sodium hydroxide.

2.2.3. Standards and Reagents. All chemicals except methanol and acetonitrile were laboratory-grade mixtures, acquired from Merck, Germany. Standards including AFB1, AFB2, AFG1, AFG2, and OTA were purchased from Supelco (Bellefonte, USA).

2.2.4. Apparatus. The detection of AFs was carried out using an HPLC apparatus (Agilent 1100 series, USA). The system was controlled by the ChemStation software. Liquid chromatography separation was performed on a reversedphase C18 $(25 \mathrm{~cm} \times 0.46 \mathrm{~mm} \times 5 \mu \mathrm{m})$, Zorbax eclipsed XDB column, from Agilent (California, USA). The fluorescence detector was set to an excitation wavelength of $365 \mathrm{~nm}$ and an emission wavelength of $435 \mathrm{~nm}$. The mobile phase consisted of a mixture of acetonitrile-methanol-water $(2: 3$ : $5, \mathrm{v} / \mathrm{v}$ ) and was filtered using a Millipore filtration apparatus, maintaining a flow rate of $1 \mathrm{ml} / \mathrm{min}^{-1}$. An electrochemical cell (model Libios-K01) was used as postcolumn derivatization. AFs were identified by their constant retention times. Calibration curves of peak areas versus aflatoxin concentrations were then plotted and used for the determination of AFs in samples. A waring blender (Middleton, MA, USA) and a water purifier (Elga, Marlow, UK) were applied for the OTA. A multiwavelength fluorescence detector (Agilent 1100 series, USA) operating at an excitation wavelength of $333 \mathrm{~nm}$ and an emission wavelength of $477 \mathrm{~nm}$ was applied. The system was controlled by the ChemStation software (Agilent 1100 series, USA). The mobile phase consisted of a combination of acetonitrile-water-acetic acid (49.5:49.5:1.0, v/v/v), and the flow rate was $1.5 \mathrm{ml} / \mathrm{min}$. The OTA was separated on a reversed-phase $\mathrm{C} 18 \quad(25 \mathrm{~cm} \times 0.46 \mathrm{~mm} \times 5 \mu \mathrm{m})$, Zorbax eclipsed XDB column, from Agilent (California, USA). The aqueous phase was filtered through a $0.45 \mu \mathrm{m}$ PTFE membrane filter (Whatman, Maidstone Kent, UK).

2.2.5. Extraction of AFs and OTA from the Spice. The samples including turmeric $(n=20)$, red pepper $(n=20)$, black pepper $(n=20)$, and cinnamon $(n=20)$ were analyzed for AFs (AFB1, AFB2, AFG1, and AFG2) and OTA with HPLC-fluorescence detector (FD), as described by the Institute of Standards and Industrial Research of Iran (ISIRI no. 6872, 2011), with some rectifications (Figure 1).

Extraction of AFs. A $50 \mathrm{~g}$ of each sample with $5 \mathrm{~g}$ of sodium chloride was placed in a $500 \mathrm{ml}$ conical bottle. $200 \mathrm{ml}$ of methanol-water $(80: 20, \mathrm{v} / \mathrm{v})$ was added to it and the mixture was homogenized using a shaker (Middleton, MA, USA) for $3 \mathrm{~min}$. The mixture was passed through a Whatman fluted filter paper, then $20 \mathrm{ml}$ of the filtrate was transferred to a glass beaker to which $130 \mathrm{ml}$ water was added. The solution 
was centrifuged at $4,000 \mathrm{rpm}$ for $10 \mathrm{~min}$ and then filtered through a BOECO glass microfiber filter.

Extraction of OTA. $25 \mathrm{~g}$ of sample and $1 \mathrm{~g}$ sodium chloride were placed in $250 \mathrm{ml}$ conical flasks. A volume of $100 \mathrm{ml}$ of acetonitrile-water $(84: 16, \mathrm{v} / \mathrm{v})$ was added and the mixture was homogenized using a Warring blender (Model MX1050XTX) for $3 \mathrm{~min}$. The mixture was passed through a Whatman fluted filter paper, and then $10 \mathrm{ml}$ of the filtrate was transferred to a glass beaker to which $40 \mathrm{ml}$ of a PBS solution was added. The solution was centrifuged at $3500 \mathrm{rpm}$ for $15 \mathrm{~min}$, as prescribed by the Institute of Standards and Industrial Research of Iran (ISIRI no. 9238, 2011).

2.2.6. Purification of AFs and OTA from Spices (IAC). $70 \mathrm{ml}$ of the filtrate was passed through the IAC Afla test (Libios) at a flow rate of $1.0 \mathrm{ml} / \mathrm{min}$. Then, $10 \mathrm{ml}$ of stilled, deionized water was passed through the IAC at a flow rate of $1 \mathrm{ml} / \mathrm{min}$. The AFs were subsequently eluted from the column, with $1.5 \mathrm{ml}$ of methanol, and collected in a glass vial; $1.5 \mathrm{ml}$ of sterilized, deionized water was also added to the vial. $100 \mu \mathrm{l}$ of eluting was injected into the HPLC.

$50 \mathrm{ml}$ of the filtrate was passed through the IAC Afla test (Libios) at a flow rate of $1.0 \mathrm{ml} / \mathrm{min}$. The OTA was then subsequently eluted from the column, with $1.5 \mathrm{ml}$ of methanol-acetic acid (98\% methanol, 2\% acetic acid) and collected in a glass vial, where $1.5 \mathrm{ml}$ of sterile, deionized water was also added. $100 \mu \mathrm{l}$ of the elute was injected into the HPLC [23].

\subsubsection{Method Validation and Quality Assurance. For AFs} linearity, a seven-point calibration curve was constructed with concentrations of $0.1,0.5,1,2,5,10$, and $20 \mu \mathrm{g} / \mathrm{kg}$ for AFB1, AFB2, AFG1, and AFG2. The calibration curves were obtained using the linear least squares regression procedure of the peak area versus the concentration. The limits of detection (LOD) and the limits of quantification (LOQ) were determined using the signal-to-noise approach, defined at that level, resulting in a signal-to-noise ratio of approximately $3: 1$ and $10: 1$, respectively. Regarding the accuracy of the method applied and because there was no certified reference material (CRM) available, $25 \mathrm{~g}$ AFTs-free sample of each spice was spiked with AFB1, AFB2, AFG1, and AFG2 at levels of 3,5 , and $10 \mu \mathrm{g} / \mathrm{kg}$. The spiked samples were analyzed by the HPLC, as described above, and then the recovery and standard deviation (SD) were calculated. All tests were carried out in three replicates.

For the OTA, a five-point calibration curve was constructed with concentrations of $0.5,2,5,10$, and $30 \mu \mathrm{g} / \mathrm{kg}$. A calibration curve was obtained using the linear least squares regression procedure of the peak area versus the concentration. The limits of detection (LOD) and of quantification (LOQ) were determined using the signal-to-noise approach, defined as per the concentration, resulting in a signal-tonoise ratio of approximately $3: 1$ and $10: 1$ for LOD and LOQ, respectively. Due to the accuracy of the method applied and since there was no certified reference material
(CRM) available, $25 \mathrm{~g}$ of different OTA-free turmeric, red pepper, black pepper, and cinnamon samples were spiked with OTA at the levels of 1,5 , and $20 \mu \mathrm{g} / \mathrm{kg}$. All the tests were carried out in three replicates, and then the recovery and standard deviation (SD) were calculated. During the day, repeatability was expressed as the relative standard deviation and compared to the reference value, as stated by the $\mathrm{Eu}$ ropean Commission no. 401. Repeatability was estimated by spiking six subsamples $(25 \mathrm{~g})$ of clean samples, at $2 \mu \mathrm{g} / \mathrm{kg}$ level of OTA, and the OTA was then determined after a week-long interval.

2.2.8. Quality Control. Furthermore, by using confirmed methods, internal and external quality control trials were conducted. Regarding the internal quality control, the precision and exactness of the methods were confirmed. For this purpose, AFB1, AFB2, AFG1, AFG2, and OTA retrievals were recorded by analyzing a blank sample, spiked at $5 \mu \mathrm{g} / \mathrm{kg}$ for AFB1 and AFG1, $1 \mu \mathrm{g} / \mathrm{kg}$ for AFB2 and AFG2, and $5 \mu \mathrm{g} /$ $\mathrm{kg}$ for OTA. The recovery rate for AFB1 was $85 \%-90 \%$ and the usual coefficient of variation was $1.4 \%$. Moreover, the recovery rate for OTA was $93 \mu \mathrm{g} / \mathrm{kg}$. The AFs and OTA levels were corrected, according to the recovery value. The LOD and LOQ for AFB1 were $0.33 \mu \mathrm{g} / \mathrm{kg}$ and $1 \mu \mathrm{g} / \mathrm{kg}$, respectively. The measurement of determination (R2) was used to calculate method linearity. A sequence of working standard solutions (total AFs $=0.05,0.10,0.50,1.0,2.5,5.0,10,20,40$, 60 , and $80 \mu \mathrm{g} / \mathrm{kg}$ ) was prepared. Calibration curves were created by distinct conspiracy area against concentration. R2 values were considered using the regression equations.

As shown in Table 1, the validation of the HPLC method was carried out in terms of linearity, the limit of detection (LOD), the limit of quantification (LOQ), accuracy and precision (RME and RSD), and recovery studies.

2.2.9. Toxin Analysis. The detection of AFs and OTA was carried out using an HPLC apparatus (Agilent 1100 series, USA). Liquid chromatography separation was performed on a reversed-phase $\mathrm{C} 18(25 \mathrm{~cm} \times 0.46 \mathrm{~mm} \times 5 \mu \mathrm{m})$, Zorbax eclipsed XDB column, from Agilent (California, USA). The fluorescence detector was set to an excitation wavelength of $365 \mathrm{~nm}$ and an emission wavelength of $435 \mathrm{~nm}$. The mobile phase consisted of a combination of acetonitrile-methanolwater $(2: 3: 5, \mathrm{v} / \mathrm{v})$. It was filtered using a Millipore filtration apparatus, maintained at a flow rate of $1 \mathrm{ml}^{-1} \mathrm{~min}^{-1}$. An electrochemical cell (model Libios-K01, France) was used as postcolumn derivatization. AFs and OTA were identified by their constant retention times. Calibration curves of peak areas versus AFs and OTA concentrations were then plotted and used for their determination in samples. A waring blender and a water purifier were utilized [24] (Figure 1).

2.2.10. Statistical Analysis. The descriptive statistics (mean, standard deviation, range) and the one-way analysis of variance (ANOVA) were conducted using an SPSS software. Statistical differences of AFs and OTA in four types of spices (turmeric, black pepper, red pepper, and cinnamon) were 
TABLE 1: Validation parameters for the HPLC determination of AFB1, AFB2, AFG1, AFG2, and OTA.

\begin{tabular}{|c|c|c|c|c|c|c|}
\hline Validation parameters & AFB1 & AFB2 & AFG1 & AFG2 & Total AFs & OTA \\
\hline LOD $(\mu \mathrm{g} / \mathrm{kg})$ & 0.1 & 0.2 & 0.3 & 0.2 & 0.6 & 0.47 \\
\hline LOQ $(\mu \mathrm{g} / \mathrm{kg})$ & 0.4 & 0.7 & 0.9 & 0.6 & 1.8 & 1.23 \\
\hline Correlation coefficient $\left(R^{2}\right)$ & 0.9989 & 0.9991 & 0.9953 & 0.9995 & 0.09978 & 0.9968 \\
\hline Recovery (\%) & $82.5-84.3$ & $74.1-83.1$ & $77.7-88.8$ & $75.0-75.9$ & $74.1-83.1$ & $83.7-99.6$ \\
\hline $\operatorname{RSD}(\%, n=20)$ & 1.31 & 3.77 & 2.35 & 2.81 & 1.77 & 1.64 \\
\hline $\operatorname{RME}(\%, n=20)$ & -3.4 & -1.0 & 1.8 & -2.1 & 1.6 & 2.6 \\
\hline
\end{tabular}

Note: RSD, relative standard deviation; RME, reversed micellar extraction; LOD, limit of detection; LOQ, limit of quantification. The bold values represent OTA.

TABLE 2: Concentration distribution of AFs.

\begin{tabular}{lcccccccc}
\hline \multicolumn{7}{c}{ Distribution of AF level $(\mu \mathrm{g} / \mathrm{kg})$ no. } \\
Samples & No. of positive/total samples & Positive* $\left.^{*}\right)$ & $<1$ & 1 to 10 & $>10$ to 20 & $>20$ & Mean $\pm \mathrm{SD}(\mu \mathrm{g} / \mathrm{kg})$ & $\mathrm{Range}(\mu \mathrm{g} / \mathrm{kg})$ \\
\hline Turmeric & $0 / 20$ & 0 & $0(0 \%)$ & $14(70 \%)$ & $0(0 \%)$ & $0(0 \%)$ & $2.84 \pm 1.08$ \\
Red pepper & $16 / 20$ & 80 & $0(0 \%)$ & $4(20 \%)$ & $8(40 \%)$ & $8(40 \%)$ & $28.21 \pm 20.8$ \\
Black pepper & $0 / 20$ & 0 & $0(0 \%)$ & $4(20 \%)$ & $0(0 \%)$ & $0(0 \%)$ & $1.53 \pm 0.62$ & $3.29-77.3$ \\
Cinnamon & $0 / 20$ & 0 & $0(0 \%)$ & $2(10 \%)$ & $0(0 \%)$ & $0(0 \%)$ & $2.04 \pm 0.04$ & $2.01-2.47$ \\
\hline
\end{tabular}

Note: * samples are considered to be positive at AF concentrations exceeding $10 \mu \mathrm{g} / \mathrm{kg}(p<0.05)$.

TABLE 3: Concentration distribution of OTA.

\begin{tabular}{lccccccc}
\hline \multicolumn{7}{c}{ Distribution of OTA level $(\mu \mathrm{g} / \mathrm{kg})$ no. } \\
Samples & No. of positive/total samples & Positive* $(\%)^{<1}$ & 1 to 15 & $>15$ & $\mathrm{Mean} \pm \mathrm{SD}(\mu \mathrm{g} / \mathrm{kg})$ & $\mathrm{Range}(\mu \mathrm{g} / \mathrm{kg})$ \\
\hline Turmeric & $0 / 20$ & 0 & $0(0 \%)$ & $2(10 \%)$ & $0(0 \%)$ & $1.07 \pm 1.0$ & $0.55-3.7$ \\
Red pepper & $0 / 20$ & 0 & $7(35 \%)$ & $4(20 \%)$ & $0(0 \%)$ & $1.52 \pm 1.78$ & $0.47-5.58$ \\
Black pepper & $20 / 20$ & 100 & $0(0 \%)$ & $0(0 \%)$ & $20(100 \%)$ & $49.29 \pm 48.4$ & $15.91-197.64$ \\
Cinnamon & $2 / 20$ & 10 & $3(15 \%)$ & $10(50 \%)$ & $2(10 \%)$ & $18.5 \pm 40.82$ & $0.7-139.44$ \\
\hline
\end{tabular}

Note: *samples are considered to be positive at OTA concentrations exceeding $15 \mu \mathrm{g} / \mathrm{kg}(p<0.05)$.

determined using the one-way ANOVA. A probability value of 0.05 was used to determine the statistical significance.

\section{Results}

All the AFs (B1, B2, G1, and G2) were well separated from each other in the standard and sample chromatogram. AFG2 was elected first, followed by AFG1, AFB2, and AFB1, respectively. According to Table 1, the linearity in the working standard solutions at three determinations of five concentration levels, was reliable between 0.9953 and 0.9995 (Table 1). The linearity of the working standard solutions at two determinations of five concentration levels was reliable (0.9997), as exhibited by the coefficient of determination, i.e., $\mathrm{R}$ squared $\left(\mathrm{R}^{2}\right)$.

The quantity of AFs in the spices (turmeric, red pepper, black pepper, and cinnamon) is summarized in Table 2. Among the 80 tested samples, 40 (50\%) were contaminated with AFs (range: $1.17-77.3 \mu \mathrm{g} / \mathrm{kg}$ ). Out of 40 contaminated samples, 20 were red pepper, 14 were turmeric, 4 were black pepper, and 2 were cinnamon spices. The mean concentration of AFs in the turmeric, red pepper, black pepper, and cinnamon spice samples was $2.84 \mu \mathrm{g} / \mathrm{kg}, 28.21 \mu \mathrm{g} / \mathrm{kg}, 1.53 \mu \mathrm{g} / \mathrm{kg}$, and $2.04 \mu \mathrm{g} / \mathrm{kg}$, respectively. Of the 80 samples, 16 samples $(20 \%)$ were above the acceptable limit AFs ( $>10 \mu \mathrm{g} / \mathrm{kg})$, which were all red pepper spice. The results of the one-way ANOVA showed that the occurrence of AFs contamination in red pepper samples was significantly more than other spice samples ( $p$ value: 0.04 ). However, there was no significant difference between black pepper, cinnamon, and turmeric samples.

Of the 80 spice samples analyzed, $48(60 \%)$ samples were contaminated with OTA, of which 20 black pepper (100\%) and 2 cinnamon (10\%) samples contained this toxin above the standard limits of detection, as proposed by the European Union $(>15 \mu \mathrm{g} / \mathrm{kg})$. As illustrated in Table 3, the mean concentration of OTA was higher in the black pepper samples. The results of the one-way ANOVA showed that OTA contamination in black pepper samples was significantly higher than other spice samples tested ( $p$ value: 0.02 ). However, there was no significant difference between red pepper, cinnamon, and turmeric samples.

The contamination of various spices with fungi is illustrated in Table 4. Out of the 20 turmeric samples, 16 samples had fungal contamination (positive culture), of which four Aspergillus section Flavi were isolated. In the red pepper spice, 17 samples had a positive culture, and in only one sample, the Aspergillus section Flavi was isolated. In the black pepper samples, 19 had fungal contamination, of which the Aspergillus 
TABLE 4: The frequency of fungal contamination of different spices according to species of fungi and number of culture positive samples.

\begin{tabular}{|c|c|c|c|}
\hline Spice & $\begin{array}{l}\text { Number of positive } \\
\text { cultures }\end{array}$ & $\begin{array}{l}\text { Aspergillus } \\
\text { section flavi }\end{array}$ & Isolated species \\
\hline Turmeric & $16 / 20$ & 4 & $\begin{array}{c}\text { Aspergillus section flavi, Aspergillus niger, Aspergillus fumigates, Mocur, } \\
\text { Pencilium, Alternaria, Acromonium }\end{array}$ \\
\hline Red pepper & $17 / 20$ & 1 & $\begin{array}{c}\text { Aspergillus section flavi, Aspergillus niger, Aspergillus fumigates, Mocur, Pencilium, } \\
\text { Acromonium }\end{array}$ \\
\hline $\begin{array}{l}\text { Black } \\
\text { pepper }\end{array}$ & $19 / 20$ & 8 & Aspergillus section flavi, Aspergillus niger, Aspergillus fumigates, Mocur, Pencilium \\
\hline Cinnamon & $16 / 20$ & 4 & Aspergillus section flavi, Aspergillus niger, Mocur, Pencilium \\
\hline
\end{tabular}

TABLE 5: The frequency of samples contaminated with mycotoxins based on culture results.

\begin{tabular}{lcccc}
\hline \multirow{2}{*}{ Culture } & \multicolumn{2}{c}{ OTA } & \multicolumn{2}{c}{ AFs } \\
& $\leq 15 \mu \mathrm{g} / \mathrm{kg}$ & $>15 \mu \mathrm{g} / \mathrm{kg}$ & $\leq 10 \mu \mathrm{g} / \mathrm{kg}$ & $>10 \mu \mathrm{g} / \mathrm{kg}$ \\
\hline Growth & $10(17.2 \%)$ & $11(50.0 \%)$ & $20(31.3 \%)$ & $1(6.3 \%)$ \\
No growth & $48(82.8 \%)$ & $11(50.0 \%)$ & $44(68.8 \%)$ & $15(93.8 .0 \%)$ \\
Total & $58(100.0 \%)$ & $22(100.0 \%)$ & $64(100.0 \%)$ & $16(100.0 \%)$ \\
\hline
\end{tabular}

section Flavi was isolated from eight samples. Furthermore, 16 cinnamon spices were contaminated with fungi, four of which contained colonies identified as Aspergillus section Flavi.

The frequency of spice samples contaminated with fungi and mycotoxins is shown in Table 5. Among the positive culture samples, only in one sample, the AFs levels were more than the permitted limit $(>10 \mu \mathrm{g} / \mathrm{kg})$. Moreover, in 15 samples with a negative culture, the level of AFs was higher than the permitted limit. Of the samples with positive fungal culture, 11 samples were contaminated with more than the allowed OTA level ( $>15 \mu \mathrm{g} / \mathrm{kg})$. Moreover, 11 samples were contaminated with an overprescribed level of OTA, which yielded negative culture results.

\section{Discussion}

Mycotoxins are unavoidable contaminants of foodstuff that pose a health threat to animals and humans. These toxic chemicals are a challenge for food safety and also develop massive country economy damages to the agriculture organization [25]. The concentration of mycotoxins can be measured by various methods such as enzyme-linked immunosorbent assay (ELISA) and HPLC. In this study, the HPLC and IAC method was used to measure mycotoxins, which has high sensitivity and specificity in comparison with the ELISA method $[26,27]$. Previous studies have reported that spices can be contaminated with fungi, resulting in mycotoxin production [28-31]. In this study, all the red pepper samples were contaminated with AFs, of which $80 \%$ of these spice samples were contaminated with AFs over permitted limit ( $>10 \mu \mathrm{g} / \mathrm{kg}$ ). In Turkey, high levels of AFs contamination (up to $40.9 \mu \mathrm{g} / \mathrm{kg}$ ) have been reported in red pepper spice [32]. Similar to the present study, recent researchers in Kenya and Qatar have reported approximately $80 \%$ AFs contamination in red pepper spices in the range of $2-99.6 \mu \mathrm{g} / \mathrm{kg}[33,34]$. In Malaysia, $55.5 \%$ of red pepper samples were contaminated with AFs ranging from 0.1 to $4.9 \mu \mathrm{g} / \mathrm{kg}$ that was lower than our results [35]. In another study, Golge et al. reported $82.5 \%$ of red pepper samples were contaminated with AFs and only $23.3 \%$ of them exceeded the legal limit [36]. Moreover, about 10\% $(n=2)$ of the cinnamon samples of our study were contaminated with AFs, which was lower than the previous reports [28, 31]. The AFs contamination of the other spices in our study was lower than the permitted level. In the current study, the concentration levels of the AFs in the black pepper and turmeric were lower than those reported by Jeswal and Kumar that found AFs in black pepper and turmeric in $76.1 \%$ and $68.5 \%$ of the samples, respectively [30].

The lower level of AFs in the black pepper, turmeric, and cinnamon might be due to the antifungal and antitoxicogenic properties of these spices [37]. The recent study reported that some spices have antifungal activity by disrupting the cell wall integrity of fungi which produce mycotoxin [38]. Furthermore, they have found that turmeric's extract can downregulate the expression of genes involved in the biosynthesis of AFs in A. flavus [39]. The amount of AFs consumed may contribute to the severe health effects [40]. In our study, one-fourth of the spice samples were contaminated with above acceptable limit of AFs that may cause serious threat over long-term consumption. In this study, all black pepper samples were contaminated with the above standard limits of OTA, as proposed by the European Union $(>15 \mu \mathrm{g} / \mathrm{kg})$. This finding was much more than those reported by Jalili (17.4\%), Jeswal and Kumar (72\%), and Salari et al. (17\%) [29, 30, 41]. The high-fat content of black pepper and the appropriate solubility of this toxin in fat may be one of the possible causes of high levels of contamination [42]. Contrary to the present study, Garcia et al. did not detect any OTA among 112 tested samples of spices [43]. In other studies from Malaysia, Tunisia, and Pakistan, OTA contamination was detected, respectively, in 56\%, 70\%, and $81 \%$ of chili powder samples, which is higher than our findings $[35,44,45]$. Moreover, in this study, $10 \%$ of cinnamon samples were contaminated with higher permissible limit of OTA, which was more than that reported by Jalili [41]. There is limited information on the fungal contamination rate in spice samples. Among the 80 spice samples cultured, $83.7 \%$ of them were contaminated with Aspergillus species, 25\% with Aspergillus section Flavi, 38.7\% with Aspergillus section Nigri, 7.5\% with Aspergillus section Fumigati, 53.7\% with Penicillium species, and $36.2 \%$ with Mucor species. These fungal contamination rates were higher than those provided by Azzoune et al. [18], which isolated Aspergillus, Penicillium, and Mucor in the spice samples at 56.4\%, 25.1\%, and $2.8 \%$, respectively. 


\section{Conclusions}

Spices are universally used in cooking and are often exported from a limited number of countries around the world. In this study, red and black peppers were contaminated with high levels of AFTs and OTA, respectively. The levels of these toxins in some samples exceeded the acceptable limits. For example, all black pepper samples were contaminated much higher than the permitted level of OTA. Majority of the mycotoxin-contaminated spice samples yielded negative culture. Moreover, $50 \%$ and $93 \%$ of these samples were contaminated with the exceeded allowable level of OTA and AFTs, respectively. This might be due to the heat stability nature of these toxins. Considering high contamination of the examined spices with mycotoxins, regular monitoring of the imported spices by heal authorities, in particular red and black peppers, is highly recommended to maintaining the food quality. Further studies are still needed to address the source of contamination and determine the mycotoxin level in the spice, from cultivation and harvesting to transport, packaging, and storage stages.

\section{Data Availability}

The data used to support the findings of this study were supplied by Shiraz University of Medical Sciences under license and so cannot be made freely available. Requests for access to these data should be made to Kamiar Zomorodian, zomorodian@sums.ac.ir.

\section{Disclosure}

This study was part of the MSc thesis of Robab Bahmyari.

\section{Conflicts of Interest}

The authors declare that they have no conflicts of interest.

\section{Acknowledgments}

This study was financially supported by the Vice-Chancellor for Research of Shiraz University of Medical Sciences (grant no. 95-01-01-12243). The authors wish to thank Mr. $\mathrm{H}$. Argasi at the Research Consultation Center (RCC) of Shiraz University of Medical Sciences for his invaluable assistance in editing this manuscript.

\section{References}

[1] L. Diniz do Nascimento, A. A. Barbosa de Moraes, K. Santana da Costa et al., "Bioactive natural compounds and antioxidant activity of essential oils from spice plants: new findings and potential applications," Biomolecules, vol. 10, no. 7, p. 988, 2020.

[2] V. M. Verma, "Black pepper: health benefits, in vitro multiplication, and commercial cultivation," in Medicinal Plants, pp. 111-127, Springer, NY, USA, 2019.

[3] A. Nag and R. R. Chowdhury, "Piperine, an alkaloid of black pepper seeds can effectively inhibit the antiviral enzymes of Dengue and Ebola viruses, an in silico molecular docking study," Virus Disease, vol. 31, no. 3, pp. 308-315, 2020.
[4] S. Shityakov, E. Bigdelian, A. A. Hussein et al., "Phytochemical and pharmacological attributes of piperine: a bioactive ingredient of black pepper," European Journal of Medicinal Chemistry, vol. 176, pp. 149-161, 2019.

[5] B. Kabak and A. D. W. Dobson, "Mycotoxins in spices and herbs: an update," Critical Reviews in Food Science and Nutrition, vol. 57, no. 1, pp. 18-34, 2017.

[6] J. Pokorná, E. Staffa, V. Bernard, and V. Mornstein, "Capsaicin effects on human facial and neck temperature," in World Congress on Medical Physics and Biomedical Engineering, vol. 2018, pp. 87-90, Springer, Singapore, 2019.

[7] G. K. Jayaprakasha and L. J. M. Rao, "Chemistry, biogenesis, and biological activities ofCinnamomum zeylanicum," Critical Reviews in Food Science and Nutrition, vol. 51, no. 6, pp. 547-562, 2011.

[8] J. E. Forsyth, S. Nurunnahar, S. S. Islam et al., "Turmeric means "yellow" in Bengali: lead chromate pigments added to turmeric threaten public health across Bangladesh," Environmental Research, vol. 179, 2019.

[9] E. Nurunnahar, A. Lucariello, M. Contieri et al., "Therapeutic effects of turmeric in several diseases: an overview," ChemicoBiological Interactions, vol. 310, 2019.

[10] M. Banerjee and P. K. Sarkar, "Microbiological quality of some retail spices in India," Food Research International, vol. 36, no. 5, pp. 469-474, 2003.

[11] M. E. Zain, "Impact of mycotoxins on humans and animals," Journal of Saudi Chemical Society, vol. 15, no. 2, pp. 129-144, 2011.

[12] N. El Darra, L. Gambacorta, and M. Solfrizzo, "Multimycotoxins occurrence in spices and herbs commercialized in Lebanon," Food Control, vol. 95, pp. 63-70, 2019.

[13] W. E. O. Campos, L. B. Rosas, A. P. Neto, R. A. Mello, and A. A. Vasconcelos, "Extended validation of a senstive and robust method for simultaneous quantification of aflatoxins B1, B2, G1 and G2 in Brazil nuts by HPLC-FLD," Journal of Food Composition and Analysis, vol. 60, pp. 90-96, 2017.

[14] S. Marchese, A. Polo, A. Ariano, S. Velotto, S. Costantini, and L. Severino, "Aflatoxin B1 and M1: biological properties and their involvement in cancer development," Toxins, vol. 10, no. 6, p. 214, 2018.

[15] FAO/WHO, Joint FAO/WHO Food Standards Programme Condex Committee on Contaminats in Foods, FAO/WHO, Rome, Italy, 2017.

[16] A. Pfohl-Leszkowicz and R. A. J. M. Manderville, "Ochratoxin A: an overview on toxicity and carcinogenicity in animals and humans," Molecular Nutrition \& Food Research, vol. 51, no. 1, pp. 61-99, 2007.

[17] D. Benford et al., Ochratoxin A. Safety Evaluation of Certain Mycotoxins in Food, pp. 281-415, World Health Organization, Geneva, Switzerland, 2001.

[18] N. Azzoune, S. Mokrane, A. Riba et al., "Contamination of common spices by aflatoxigenic fungi and aflatoxin B1in Algeria," Quality Assurance and Safety of Crops \& Foods, vol. 8, no. 1, pp. 137-144, 2015.

[19] M. A. Klich, Identification of Common Aspergillus Species, Centraalbureau voor Schimmelcultures, Utrecht, The Netherlands, 2002.

[20] J. Pitt, A Laboratory Guide to Common Penicillium Species, CSIRO, Australia, 1988.

[21] M. Orlowski, "Mucor dimorphism," Microbiological Reviews, vol. 55, no. 2, pp. 234-258, 1991.

[22] F. Zaini, A. Mehbod, and M. Emami, Comprehensive Medical Mycology, Tehran University, vol. 1377, pp. 330-48, Tehran, Iran, 3rd edition, 2013. 
[23] M. N. Hossain, A. Talukder, F. Afroze et al., "Identification of aflatoxigenic fungi and detection of their aflatoxin in red chilli," Advances in Microbiology, vol. 8, no. 1, pp. 42-53, 2018.

[24] L. Zhang, X.-W. Dou, C. Zhang, A. F. Logrieco, and M.-H. Yang, "A review of current methods for analysis of mycotoxins in herbal medicines," Toxins, vol. 10, no. 2, p. 65, 2018.

[25] A. Alshannaq and J.-H. Yu, "Occurrence, toxicity, and analysis of major mycotoxins in food," International Journal of Environmental Research and Public Health, vol. 14, no. 6, p. $632,2017$.

[26] L. Gambacorta, D. Magistà, G. Perrone, S. Murgolo, A. F. Logrieco, and M. Solfrizzo, "Co-occurrence of toxigenic moulds, aflatoxins, ochratoxin A, Fusarium and Alternaria mycotoxins in fresh sweet peppers (Capsicum annuum) and their processed products," World Mycotoxin Journal, vol. 11, no. 1, pp. 159-174, 2018.

[27] L. Motloung, S. De Saeger, M. De Boevre et al., "Study on mycotoxin contamination in South African food spices," World Mycotoxin Journal, vol. 11, no. 3, pp. 401-409, 2018.

[28] M. Jalili, "Natural occurrence of aflatoxins contamination in commercial spices in Iran," Iranian Journal of Health, Safety \& Environment, vol. 3, no. 2, pp. 513-517, 2016.

[29] R. Salari, M. B. Habibi Najafi1, M. T. Boroushaki, S. A. Mortazavi, and M. Fathi Najafi, "Assessment of the microbiological quality and mycotoxin contamination of Iranian red pepper spice," Journal of Agricultural Science and Technology, vol. 14, pp. 1511-1521, 2012.

[30] P. Jeswal and D. Kumar, "Mycobiota and natural incidence of aflatoxins, ochratoxin A, and citrinin in Indian spices confirmed by LC-MS/MS," International Journal of Microbiology, vol. 2015, Article ID 242486, 2015.

[31] F. Ozbey and B. Kabak, "Natural co-occurrence of aflatoxins and ochratoxin A in spices," Food Control, vol. 28, no. 2, pp. 354-361, 2012.

[32] O. Golge, F. Hepsag, and B. Kabak, "Incidence and level of aflatoxin contamination in chilli commercialised in Turkey," Food Control, vol. 33, no. 2, pp. 514-520, 2013.

[33] W. Hammami, S. Fiori, R. Al Thani et al., "Fungal and aflatoxin contamination of marketed spices," Food Control, vol. 37, pp. 177-181, 2014.

[34] W. W. Mwangi, C. M. Nguta, and B. G. Muriuki, "Aflatoxin contamination in selected spice preparations in the Nyahururu retail market, Kenya," Journal of Scientific Research and Reports, vol. 3, no. 7, pp. 917-923, 2014.

[35] M. Jalili and S. Jinap, "Natural occurrence of aflatoxins and ochratoxin A in commercial dried chili," Food Control, vol. 24, no. 1-2, pp. 160-164, 2012.

[36] O. Golge, F. Hepsag, and B. Kabak, "Determination of aflatoxins in walnut sujuk and Turkish delight by HPLC-FLD method," Food Control, vol. 59, pp. 731-736, 2016.

[37] G. M. Parvez, "Current advances in pharmacological activity and toxic effects of various Capsicum species," International Journal of Pharmaceutical Sciences and Research, vol. 8, no. 5, pp. 1900-1912, 2017.

[38] F. Hu, X.-F. Tu, K. Thakur et al., "Comparison of antifungal activity of essential oils from different plants against three fungi," Food and Chemical Toxicology, vol. 134, 2019.

[39] R. Sandhu, S. Dahiya, P. Sayal, and D. Budhani, "Increased role of nonalbicans Candida, potential risk factors, and attributable mortality in hospitalized patients," Journal of Health Research and Reviews, vol. 4, no. 2, pp. 78-83, 2017.

[40] K. Pakshir, Z. Mirshekari, H. Nouraei et al., "Mycotoxins detection and fungal contamination in black and green tea by
HPLC-based method," Journal of Toxicology, vol. 2020, Article ID 2456210, , 2020.

[41] M. Jalili, "Natural occurrence of ochratoxin A contamination in commercial spices in Tehran," Nutrition and Food Sciences Research, vol. 3, no. 3, pp. 25-30, 2016.

[42] A. Papachristou and P. Markaki, "Determination of ochratoxin A in virgin olive oils of Greek origin by immunoaffinity column clean-up and high-performance liquid chromatography," vol. 21, no. 1, pp. 85-92, 2004.

[43] M. V. Garcia, C. A. Mallmann, and M. V. Copetti, "Aflatoxigenic and ochratoxigenic fungi and their mycotoxins in spices marketed in Brazil," Food Research International, vol. 106, pp. 136-140, 2018.

[44] S. Z. Iqbal, R. R. M. Paterson, I. A. Bhatti, and M. R. Asi, "Survey of aflatoxins in chillies from Pakistan produced in rural, semi-rural and urban environments," Food Additives and Contaminants, vol. 3, no. 4, pp. 268-274, 2010.

[45] C. Zaied, S. Abid, C. Bouaziz, S. Chouchane, M. Jomaa, and H. Bacha, "Ochratoxin A levels in spices and dried nuts consumed in Tunisia," Food Additives and Contaminants: Part B, vol. 3, no. 1, pp. 52-57, 2010. 